\title{
Determinants of the range of drugs prescribed in general practice:
} a cross-sectional analysis

\author{
Dinny H de Bakker*1, Dayline SV Coffie ${ }^{1}$, Eibert R Heerdink ${ }^{2}$, Liset van Dijk ${ }^{1}$ \\ and Peter P Groenewegen ${ }^{1,3}$
}

\begin{abstract}
Address: ${ }^{1}$ NIVEL Netherlands institute for health services research, PO Box 1568, Utrecht, The Netherlands, ${ }^{2}$ Utrecht University, Department of Pharmacoepidemiology and Pharmacotherapy, Utrecht, The Netherlands and ${ }^{3}$ Utrecht University, Department of Human Geography and Department of Sociology, Utrecht, The Netherlands

Email: Dinny H de Bakker* - d.debakker@nivel.nl; Dayline SV Coffie - dayline@mail.com; Eibert R Heerdink - e.r.heerdink@pharm.uu.nl; Liset van Dijk - l.vandijk@nivel.nl; Peter P Groenewegen - p.groenewegen@nivel.nl

* Corresponding author

Published: 22 August 2007

BMC Health Services Research 2007, 7:132 doi:10.1 186/1472-6963-7-132

Received: 2I November 2006

Accepted: 22 August 2007

This article is available from: http://www.biomedcentral.com//472-6963/7//132

(c) 2007 de Bakker et al; licensee BioMed Central Ltd.

This is an Open Access article distributed under the terms of the Creative Commons Attribution License (http://creativecommons.org/licenses/by/2.0), which permits unrestricted use, distribution, and reproduction in any medium, provided the original work is properly cited.
\end{abstract}

\begin{abstract}
Background: Current health policies assume that prescribing is more efficient and rational when general practitioners (GPs) work with a formulary or restricted drugs lists and thus with a limited range of drugs. Therefore we studied determinants of the range of drugs prescribed by general practitioners, distinguishing general GP-characteristics, characteristics of the practice setting, characteristics of the patient population and information sources used by GPs.
\end{abstract}

Methods: Secondary analysis was carried out on data from the Second Dutch Survey in General Practice. Data were available for 138 GPs working in 93 practices.

ATC-coded prescription data from electronic medical records, census data and data from GP/ practice questionnaires were analyzed with multilevel techniques.

Results: The average GP writes prescriptions for 233 different drugs, i.e. $30 \%$ of the available drugs on the market within one year. There is considerable variation between ATC main groups and subgroups and between GPs. GPs with larger patient lists, GPs with higher prescribing volumes and GPs who frequently receive representatives from the pharmaceutical industry have a broader range when controlled for other variables.

Conclusion: The range of drugs prescribed is a useful instrument for analysing GPs' prescribing behaviour. It shows both variation between GPs and between therapeutic groups. Statistically significant relationships found were in line with the hypotheses formulated, like the one concerning the influence of the industry. Further research should be done into the relationship between the range and quality of prescribing and the reasons why some GPs prescribe a greater number of different drugs than others.

\section{Background}

Prescribing a drug is one of the most frequent therapeutical decisions by general practitioners (GPs). There are numerous different drugs on the market, which means that GPs usually have a choice of several different drugs even when treating the same health problem. The aggre- 
gated costs for prescription drugs are high and increasing, however, and several policy initiatives have therefore been implemented against the background of this spiralling expense. One such initiative is to restrict GP prescribing to drugs that are on an indicative drug list, which was introduced in the UK.

In the absence of an indicative drug list in the Netherlands, it is important to know what influences the range that GPs prescribe. In the Netherlands, 75 percent of all drugs are prescribed by GPs and $65 \%$ of consultations end with a prescription [1]. Moreover, drug costs are rising sharply and they constitute an important expense in health care [2]. Current health policies assume that prescribing is more efficient and rational when GPs work with formulary or restricted drugs lists and thus with a limited range of drugs $[3,4]$. An advantage of using a limited range of drugs is that GPs become more familiar with drug dosages, contra-indications, interactions, etc., resulting in a lower incidence of side effects and dangerous interactions $[5,6]$. Especially, the number of analogue drugs (drugs consisting of various chemical substances, but used for the same condition) should be limited [6]. This should translate into lower costs [7].

There have been previous studies of the prescribing patterns of GPs, but most studies focused on differences in the total amount of prescriptions or on prescriptions for a particular group of drugs [8-10]. Little is known to date about the variation in the numbers of different drugs (the range) that GPs prescribe and about the factors that might explain these variations between GPs. Two studies showed that the number of doctors in the practice is positively related to the range of drugs prescribed $[6,11]$. The last study also found higher ranges in practices with high patient lists per doctor, a high percentage of elderly and a heavy workload. One study found no consistent relationship between the adoption of new drugs and previous prescribing of drugs belonging to the same therapeutic class [12]. Taylor e.a. linked GP characteristics (including their information sources) to prescribing in terms of adding new drugs to their repertory [13]. Another study showed that for two out of six therapeutic groups there was a positive association between number of years in practice and range of drugs [14].

The purpose of this study is to determine whether there is variation between GPs in the range of drugs they prescribe and whether there is variation within therapeutic groups of drugs, and how these differences can be explained. Our analysis is at the level of GPs where most recent studies were at practice level. Secondly, more determinants were taken into consideration, especially with respect to the GPs' information sources and the influence of patient characteristics.

\section{Hypotheses}

It can be expected that known determinants of rational prescribing are also relevant in explaining the variation in the range of drugs prescribed. These determinants partly relate to individual GPs' prescribing decisions $[15,16]$. Differences in the range of drugs prescribed will also depend on individual GP characteristics, the practice setting in which he works and the composition of the practice population [17]. Further the way GPs acquire knowledge about new drugs might play a role [18].

First, individual characteristics of GPs might influence the range. Gender of the GP is not assumed to be directly related to the range of drugs prescribed. The age of the GP might have an influence in so far as age indicates years of experience. The direction of the relationship is difficult to hypothesize beforehand, however, because age (more experience) might be related to a smaller range of drugs (as a consequence of less uncertainty) or to a broader range (as a consequence of less up-to-date knowledge on pharmacotherapy). The individual list size might be positively related to the range of drugs simply because a higher number of patients increases the chance on a wider range of drugs. Further we can assume that GPs that are more inclined to prescribe in general might also be inclined to prescribe more different drugs.

Second, the practice setting in which the GP works might be of influence. Previous research showed that the number of doctors in the practice was positively related to the range at practice level $[6,11]$, which could be explained by the fact that the combined repertory of more doctors will generally be larger than those of individual doctors. This does not mean, however, that individual GPs within group practices have larger ranges, although the fact that patients tend to switch between GPs in a group practice might influence the range positively. Dispensing practices might have a smaller range of drugs (as a consequence of more pharmaco-therapeutic knowledge, or for simple economic reasons of wanting to restrict the number of drugs in stock), but data for dispensing practices might also contain drugs that were prescribed by hospital consultants, which would result in a broader range.

Third, the practice population might influence the range of drugs prescribed. In general a more complex practice population is hypothesized to be related to a broader range of drugs prescribed, as a consequence of greater use of health services, worse health and more diverse health problems of urban residents, especially where mental health is concerned. So we expect a broader range in urban areas, especially in deprived areas, in practices with a high percentage of elderly and patients from non-western origin $[16,19,20]$. More people with higher education and fewer publicly insured people in a practice might be related to a 
broader range (the higher educated may be more demanding and new drugs are not always reimbursable for publicly insured patients).

Finally the GPs' pharmaceutical information sources especially on new drugs might play a role. In general it can be assumed that GPs who use independent sources of information will prescribe a smaller range of drugs, because independent sources will stress the 'me too' character of many new drugs[3,9,15,21]. Collaboration between GP and pharmacist can lead to more restricted formulary based prescribing $[22,23]$. Reliance on the pharmaceutical industry as a source of information is assumed to be related to a broader range of drugs prescribed, because these sources will stress the advantages of new drugs $[3,9,21,24-26]$.

\section{Methods}

Data were analyzed from the Second Dutch National Survey of General Practice, a large scale study held in 2001. Data were collected in 104 computerized general practices with 195 GPs serving a population of approximately 400,000 residents. The data include background information on the patients involved, collected from the practice computer (list size, insurance type) and via a census (e.g. education, ethnicity, occupation), approximately 14,000 health interview surveys, and 1.4 million electronically coded medical records (consultations, diagnosis, prescriptions, referrals) kept of all patients contacting the GP in 2000/1 [27]. Further information on GP and practice characteristics were collected with GP/practice questionnaires. The GP questionnaire included factors affecting GP prescribing behaviour. The Second Dutch National Survey of General Practice was carried out according to Dutch legislation on privacy. The privacy regulation of the study was approved by the Dutch Data Protection Authority.

Prescription data that could be traced to individual GPs were selected from the electronic medical records. Only GPs with more than 500 prescribed medications were included. This resulted in data for 138 GPs working in 93 practices.

Ninety-two percent of all medication prescribed was classified by active substance according to the Anatomical Therapeutical Chemical (ATC) classification code developed by the World Health Organisation (WHO) [28].

\section{Measurement of the range (dependent variable)}

We define the range as the number of different drugs prescribed within a certain ATC-system main group (ATC 3) (Table 1), thereby focusing on the number of analogue drugs [6]. Not all the therapeutic groups within the ATCsystem were relevant for this study. Some therapeutic groups were excluded for reasons that included the following:

- they offered too little drug choice; only a few drugs are available within these groups (e.g. N07: other CNS drugs, including parasympathomimetics)

- they concerned an unusual disorder which has a very low prevalence (e.g. H: systemic hormonal preparations excluding sex hormones)

- they concerned diseases which are treated only by specialists and not by GPs (e.g. L: antineoplastic and immunosuppressive drugs)

On the other hand, there were some important subgroups (ATC-4) for which it would be favourable to determine the range for these groups separately, e.g. the anti-psychotics (N05A), the anti-depressants (N06A), etc.

ATC codes were recorded at GP level. The explanatory analysis used an overall score for the range, instead of separate range values for the different therapeutic groups. This score was computed by summing the ranges over the ATC3/ATC4 subgroups (see total in table 1). Factor analysis showed that the scores for the various subgroups were unidimensional.

\section{Measurement of the explanatory variables}

The following explanatory variables were included in the analysis. Unless otherwise indicated, these were derived from the GP/practice questionnaires.

\section{GP background characteristics \\ - Age and gender of the GP. \\ - Individual list size (practice computer).}

Practice characteristics

- Type of practice (single-handed, duo, group; entered as dummy variables in the analysis),

- dispensing practice,

- number of prescriptions per listed patient per year (electronic medical records/practice computer): we hypothesized a relationship at GP-level. Because of data problems we had to include this variable at practice level, however.

\section{Practice population characteristics}

- Degree of urbanization (as classified by Statistics Netherlands on a five-point scale ranging from not urbanized to very strongly urbanized; entered as dummy variables in the analysis), 
Table I: Mean and variation between GPs in range of the selected therapeutical main or subgroups*

\begin{tabular}{|c|c|c|c|c|c|c|c|}
\hline & ATC & Average range & $\begin{array}{l}\text { Coefficient of } \\
\text { variation }\end{array}$ & Min & Max & $\begin{array}{l}\text { Number of } \\
\text { drugs on } \\
\text { the market }\end{array}$ & $\begin{array}{l}\text { Range as \% of } \\
\text { drugs on the } \\
\text { market }\end{array}$ \\
\hline Antacids, drugs for treatment of peptic ulcers/flatulence & $\mathrm{A} 02$ & 10.90 & 28.85 & 3 & 20 & 32 & 34.1 \\
\hline Laxatives & A06 & 7.41 & 32.60 & 2 & 13 & 24 & 30.9 \\
\hline Drugs used in diabetes & A 10 & 8.80 & 26.02 & 3 & 14 & 17 & 51.8 \\
\hline Insulins & AIOA & 3.78 & 38.15 & 1 & 7 & 7 & 54.0 \\
\hline Oral blood glucose lowering drug & AIOB & 5.12 & 22.56 & 2 & 7 & 10 & 51.2 \\
\hline Antithrombotic agents & BOI & 5.95 & 26.27 & 1 & 10 & 27 & 22.0 \\
\hline Cardiac therapy & $\mathrm{COI}$ & 6.06 & 26.06 & 1 & 10 & 32 & 18.9 \\
\hline Diuretics & $\mathrm{C} 03$ & 7.04 & 20.04 & 3 & 9 & 15 & 46.9 \\
\hline Beta blocking agents & $\mathrm{C} 07$ & 8.31 & 26.56 & 4 & 15 & 26 & 32.0 \\
\hline Agents acting on the renin-angiotensin system & $\mathrm{C} 09$ & 12.09 & 31.30 & 3 & 22 & 31 & 39.0 \\
\hline Antifungals for dermatological use & DOI & 6.89 & 26.69 & 2 & 12 & 17 & 40.5 \\
\hline Corticosteriods, dermatological preparations & D07 & 12.43 & 25.40 & 5 & 22 & 27 & 46.0 \\
\hline Sex hormones and modulators of the genital system & G03 & 21.70 & 24.78 & 9 & 36 & 56 & 38.8 \\
\hline Hormonal contraceptives for systemic use & G03A & 9.30 & 22.71 & 4 & 14 & 17 & 54.7 \\
\hline Estrogens & G03C & 2.89 & 24.98 & I & 5 & 6 & 48.2 \\
\hline Rest of G03 (G03REST) & & 9.51 & 37.70 & 2 & 19 & 33 & 28.8 \\
\hline Antibacterials for systemic use & j0I & 17.18 & 15.98 & 10 & 24 & 79 & 21.7 \\
\hline Anti-inflammatory and antirheumatic products & $\mathrm{MOI}$ & 9.02 & 26.04 & 4 & 17 & 25 & 36.1 \\
\hline Anti-inflammatory/-rheumatic products. non-steriods & MOIA & 8.92 & 25.53 & 4 & 17 & 22 & 40.5 \\
\hline Analgesics & N02 & 12.62 & 23.49 & 4 & 21 & 40 & 31.6 \\
\hline Opioids & N02A & 4.33 & 28.91 & I & 7 & 17 & 25.5 \\
\hline Other analgesics and antipyretics & N02B & 3.80 & 23.55 & 1 & 6 & 13 & 29.2 \\
\hline Antimigraine preparations & No2C & 4.48 & 38.55 & 1 & 9 & 10 & 44.8 \\
\hline Psycholeptics & N05 & 21.70 & 27.61 & 6 & 37 & 76 & 28.6 \\
\hline Antipsychotics & N05A & 7.85 & 45.58 & 1 & 22 & 31 & 25.3 \\
\hline Anxiolytics & N05B & 7.19 & 27.84 & 2 & 12 & 16 & 44.9 \\
\hline Hypnotics and sedatives & N05C & 6.83 & 25.36 & 2 & 11 & 29 & 23.6 \\
\hline Psychoanaleptics & N06 & 12.48 & 24.26 & 4 & 19 & 33 & 37.8 \\
\hline Antidepressants & N06A & 11.24 & 23.32 & 4 & 17 & 24 & 46.8 \\
\hline Nasal preparations & ROI & 7.92 & 24.17 & 3 & 12 & 17 & 46.6 \\
\hline Anti-asthmatics & R03 & 12.86 & 20.55 & 6 & 20 & 26 & 49.5 \\
\hline Cough and cold preparations & R05 & 4.34 & 36.89 & I & 9 & 22 & 19.7 \\
\hline Antihistamines for systemic use & R06 & 10.20 & 27.96 & 3 & 17 & 25 & 40.8 \\
\hline Ophthalmologicals & SOI & 16.98 & 41.17 & 5 & 39 & 79 & 21.5 \\
\hline Overall Range & & 232.87 & 20.61 & 111 & 353 & 755 & 30.8 \\
\hline
\end{tabular}

\footnotetext{
*compared to the number of drugs on the market in 2001.
} 
- practice located in deprived urban area (as classified for additional remuneration of GPs [27]),

- \% of practice population older than 75 years (practice computer),

- \% of practice population with higher education, according to definition Statistics Netherlands (census),

- \% of practice population publicly insured (practice computer),

- \% of practice population of non-western origin according to definition (census).

\section{GPs' pharmaceutical information sources}

- Participation in postgraduate courses (hours per year),

- participation in Pharmaco-therapeutic Audit Meetings (frequency per year),

- number of different written sources (max. 4) used for information on new drugs,

- number of different oral sources (max. 3) used for information on new drugs,

- number of representatives of pharmaceutical industry received in the last four weeks,

- mean frequency of use of independent information sources like guidelines and formularies (4 item five-point scale ranging from never to often, $\alpha=.64$ ),

- mean frequency of use of information sources in the pharmaceutical industry (on a five-point scale ranging from never to often, $\alpha=.65$ ).

The scales on frequency of use of independent information and information from industry appeared to be independent factors in a factor analysis with all information items [21].

\section{Analysis}

Descriptive information is given for the range per ATC group. The coefficient of variation (equal to (standard deviation/mean)*100) is given instead of the standard deviation because this enables comparison between ATCgroups. Bivariate (Pearson) correlation coefficients were computed between the explanatory variables and with the overall range. Multiple regression analysis was used to examine the joint relationship between the dependent variable and the explanatory variables. Hypotheses were tested one-tailed with a significance of $p<0.05$, where we had a directional hypotheses and two-tailed when there was no directional hypotheses. The regression analysis was performed using multilevel analysis [30,31], due to the dependence of the observations for GPs working in the same practice.

\section{Results}

Table 1 shows the ranges for the therapeutic main groups and subgroups selected. The range is of course dependent on the number of drugs on the market and the number of drugs on the market was therefore placed as a reference category, while the range was also computed as a percentage of the number of drugs on the market. We see clear variation between different therapeutic groups in the percentages of available drugs used. In the case of cardiac therapy (C01), antibacterials (J01), antithrombotic agents (B01) and hypnotics and sedatives (N05C), the average GP uses less than $25 \%$ of the available drugs on the market. In contrast, more than $50 \%$ of all available insulins (A10A), hormonal contraceptives (G03A), drugs used in diabetes (A10) and oral blood glucose lowering drugs (A10B) are used by the average GP. If we look at all therapeutic main groups together, the average GP uses 233 different drugs or $31 \%$ of the drugs available on the market.

The second type of variation we can perceive in the table is between GPs. The total number of drugs prescribed varies between 111 and 353, or between $15 \%$ and $47 \%$ of the available drugs on the market. There are differences between therapeutic main groups and subgroups in this respect, the coefficient of variation ranging from 16 for antibacterials to 46 for antipsychotics. The fact that for both these drug groups the range as a percentage of available drugs used was low shows that a low range as a percentage of available drugs used does not imply automatically little variation between GPs.

Descriptive information of the explanatory variables used has been given in table 2, which also shows the relationship of these variables with the overall range. The range is statistically significantly larger in non-urbanized areas, in dispensing practices, for GPs with larger patient lists, in practices with more patients with higher education, in practices that frequently received representatives of the pharmaceutical industry and more frequently used information sources of the industry, and in practices with a high prescription volume per patient. We see a statistically significant smaller range for GPs working in deprived urban areas. Table 3 shows the statistically significant correlation coefficients between the explanatory variables. The correlations are moderate at most, which means that they can be entered together in a multivariate analysis.

The results of the multilevel analysis are shown in table 4 . In the empty model (without explanatory variables), we found that the amount of variation at GP-level differed 
Table 2: Independent variables: descriptive characteristics and bivariate correlations with overall range, tested one-tailed*

\begin{tabular}{|c|c|c|c|}
\hline & mean $/ \%$ & Sd & $\begin{array}{l}\text { corr. with } \\
\text { range }\end{array}$ \\
\hline Age GP (mean/sd) ${ }^{\mathrm{a}}$ & 47.7 & 6.1 & 0.05 \\
\hline Gender GP (\% female $)^{\mathrm{a}}$ & 20 & & -0.09 \\
\hline \multicolumn{4}{|l|}{ Type of practice } \\
\hline Single-handed (\%) & 35 & & 0.07 \\
\hline duo practice (\%) & 25 & & 0.13 \\
\hline Group practice (\%) & 40 & & -0.04 \\
\hline \multicolumn{4}{|l|}{ Degree of urbanisation } \\
\hline very strong $(\%)$ & 17 & & -0.15 \\
\hline Strong $(\%)$ & 23 & & 0.00 \\
\hline moderate (\%) & 18 & & -0.04 \\
\hline little (\%) & 30 & & 0.01 \\
\hline not $(\%)$ & 12 & & $0.20 *$ \\
\hline Deprived urban area (\%) & 9 & & $-0.17^{*}$ \\
\hline Dispensing practice $(\%)^{* *}$ & 10 & & $0.25^{*}$ \\
\hline Individual list size (mean/sd) & 2193 & 560 & $0.26 *$ \\
\hline$\%$ patients > 75 yrs (mean/sd) & 6.1 & 2.8 & 0.07 \\
\hline $\begin{array}{l}\text { \% patients with higher education } \\
(\mathrm{mean} / \mathrm{sd})\end{array}$ & 23.1 & 11.5 & $0.22 *$ \\
\hline$\%$ patients publicly insured (mean/sd) & 66.9 & 8.7 & 0.12 \\
\hline $\begin{array}{l}\% \text { patients of non-western origin } \\
(\mathrm{mean} / \mathrm{sd})\end{array}$ & 6.5 & 11.8 & -0.01 \\
\hline $\begin{array}{l}\text { Hours per year postgraduate } \\
\text { courses (mean/sd) }\end{array}$ & 55.4 & 62.2 & -0.05 \\
\hline $\begin{array}{l}\text { Participation per year in pharm. } \\
\text { meetings (mean/sd) }\end{array}$ & 7.5 & 4.1 & 0.00 \\
\hline $\begin{array}{l}\text { Use written information sources } \\
\text { (mean/sd) }\end{array}$ & 2.1 & 1.2 & 0.13 \\
\hline $\begin{array}{l}\text { Use oral information sources (mean/ } \\
\text { sd) }\end{array}$ & 1.7 & 1.1 & -0.10 \\
\hline $\begin{array}{l}\text { Visits (last } 4 \text { weeks) representatives } \\
\text { pharm. ind. (mean/sd) }\end{array}$ & 2 & 2.9 & $0.18^{*}$ \\
\hline $\begin{array}{l}\text { Use independent information } \\
\text { sources (mean/sd) }\end{array}$ & 3.9 & 0.8 & -0.10 \\
\hline $\begin{array}{l}\text { Use information sources industry } \\
\text { (mean/sd) }\end{array}$ & 1.4 & 0.6 & $0.15^{*}$ \\
\hline $\begin{array}{l}\text { Prescriptions per patient per year } \\
\text { (mean/sd) }\end{array}$ & 6.5 & 11.8 & $0.38^{*}$ \\
\hline
\end{tabular}

$* \mathrm{p}<0.05$.

** Where there was no directional hypothesis two-tailed testing was applied

significantly from zero. There was no significant variation at practice level.

The clustering of GPs within practices - the intraclass correlation - is relatively strong, which means that the ranges for GPs in the same practices are correlated $(0.312$ in the full model). Table 4 shows that the prescribing volume at practice level was significantly and positively related to the overall range, which also applied at GP level to the individual list size and the frequency of visits of representatives of the pharmaceutical industry at practice level. All of this confirms our hypotheses.
Other hypotheses were not confirmed. We did not find that urban location is related to a broader range, nor did we find wider ranges in group practices, in practices with a high proportion of elderly patients, a high proportion of people with higher education or a low proportion of publicly insured people. In the field of pharmaceutical knowledge, we did not find significant relationships with access to independent information sources or participation in Pharmaco-Therapeutic Audit Meetings. Multiple regression analysis showed that $38 \%$ of the total variance could be explained by the variables used.

\section{Discussion}

In this article, we analyzed the concept of the range of drugs prescribed as an alternative or supplement to more usual measurements like the total number of prescriptions. The material in this article shows this to be a useful addition, especially when more precise clinical indicators are absent. Firstly because the range shows clear variations between ATC main groups and subgroups, and between GPs; secondly because it was possible to explain the variation between GPs by factors that have a theoretically interpretable relationship to the range. GPs with larger patient lists, GPs with higher prescribing volumes and GPs who frequently receive representatives from the pharmaceutical industry turned out to have a broader range when controlled for other variables. These statistical relationships could be linked to the hypotheses we formulated on the basis of the literature or theoretical considerations.

A measure which is comparable to the range is DU90\% (the number of drugs constituting $90 \%$ of the volume expressed in DDDs). This has been used for GP data in Stockholm, Sweden, as a general quality indicator in feedback $[32,33]$. In an intervention project aimed at decreasing the number of inhabitants per GP, no systematic change in DU90\% could be detected [33].

For measures of prescribing variation, ideally, guideline recommendations should be taken into account. Bergman e.a. [32] did not find a relationship between DU90\% and adherence to a local formulary. The theoretical link between the range of drugs prescribed and quality of drug prescribing is based on the use of restrictive formularies or guidelines. This link was not studied in our article. It would require specific information on the indication to prescribe and on the link between indications and guidelines or formularies. However, in the absence of detailed information on indications, the range of drugs could be used as an overall measure in addition to other drug-specific measures [34].

The relationship of the range of drugs prescribed with the number of prescriptions per patient and list size can be 
Table 3: Pearson correlation coefficients between explanatory variables (only significant correlations. $p<0.05$ )

\begin{tabular}{|c|c|c|c|c|c|c|c|c|c|c|c|c|c|c|c|c|c|c|c|c|c|c|c|c|c|}
\hline & & 1 & 2 & 3 & 4 & 5 & 6 & 7 & 8 & 9 & 10 & 11 & 12 & 13 & 14 & 15 & 16 & 17 & 18 & 19 & 20 & 21 & 22 & 23 & 24 \\
\hline 1 & age GP & & & & & & & & & & & & & & & & & & & & & & & & \\
\hline 2 & female GP & -0.31 & & & & & & & & & & & & & & & & & & & & & & & \\
\hline 3 & single handed & & -0.17 & & & & & & & & & & & & & & & & & & & & & & \\
\hline 4 & duo practice & & & -0.42 & & & & & & & & & & & & & & & & & & & & & \\
\hline 5 & group practice & & 0.27 & -0.60 & -0.47 & & & & & & & & & & & & & & & & & & & & \\
\hline 6 & very strong urban & & & 0.24 & & -0.17 & & & & & & & & & & & & & & & & & & & \\
\hline 7 & strong urban & & & & & & -0.25 & & & & & & & & & & & & & & & & & & \\
\hline 8 & moderate urban & & & & & & -0.21 & -0.26 & & & & & & & & & & & & & & & & & \\
\hline 9 & little urban & & & -0.28 & & 0.31 & -0.29 & -0.36 & -0.31 & & & & & & & & & & & & & & & & \\
\hline 10 & not urban & & & & & & & -0.20 & -0.17 & -0.24 & & & & & & & & & & & & & & & \\
\hline 11 & deprived urban area & & 0.28 & & & & 0.59 & & & -0.21 & & & & & & & & & & & & & & & \\
\hline 12 & dispensing & & & & & & & -0.19 & & & 0.40 & & & & & & & & & & & & & & \\
\hline 13 & individual list size & & -0.37 & 0.36 & & -0.37 & & & 0.25 & & & -0.26 & & & & & & & & & & & & & \\
\hline 14 & $\%>75$ yrs & & -0.24 & & & -0.27 & & & & -0.18 & & & & & & & & & & & & & & & \\
\hline 15 & $\%$ higher education & & & & & & 0.36 & 0.20 & & -0.24 & -0.21 & 0.54 & -0.19 & & & & & & & & & & & & \\
\hline 16 & $\%$ sick fund insured & & & & & & & & & & & & & & & -0.60 & & & & & & & & & \\
\hline 17 & $\%$ non-western & & 0.20 & 0.26 & & -0.18 & 0.52 & & & -0.23 & & 0.36 & & & & & 0.45 & & & & & & & & \\
\hline 18 & postgraduate courses & & & & & & 0.17 & & & & & & & & 0.19 & & & & & & & & & & \\
\hline 19 & part. pharm. meetings & & & & & & & & & & & & & & & & & & & & & & & & \\
\hline 20 & written info sources & & & & & -0.17 & & & & & & & & 0.17 & & & & & & & & & & & \\
\hline 21 & oral info sources & & & & -0.17 & 0.21 & 0.20 & & & & & & -0.24 & & & & & & & & & & & & \\
\hline 22 & visits repres. ind. & & -0.21 & 0.39 & & -0.34 & & & 0.35 & -0.28 & & & & 0.38 & & & & & & & 0.31 & & & & \\
\hline 23 & use indep. sources & & & & & & & & & 0.24 & & & & -0.20 & & & & & & 0.19 & & & -0.29 & & \\
\hline 24 & use sources ind. & & & 0.22 & & & & & & & & & & & & & & & & & 0.29 & & 0.41 & & \\
\hline 25 & prescriptions per patient & & & & & & -0.18 & & & & 0.55 & & 0.43 & -0.18 & 0.29 & -0.35 & 0.24 & & & & & & & & \\
\hline
\end{tabular}


Table 4: Multilevel regression analysis of the explanatory variables on the overall range of different medicines prescribed by GPs in 2001

\begin{tabular}{cccc}
\hline & Empty model & Full model \\
\hline practice level fixed effects & Estimate (standard error) & Estimate (standard error) & Hypothesis \\
- prescriptions per patient & & $0.2583(0.1005)^{*}$ & Confirmed \\
GP level fixed effects: & & & $0.9289(0.0456)^{*}$ \\
- visits representatives industry & & $0.0000765(0.0002074)^{*}$ & Confirmed \\
- individual list size & & & Confirmed \\
variance components: & & $0.2684(0.1424)$ & \\
practice level intercept & & $0.5914(0.1324)^{*}$ \\
GP level intercept & $0.8419(0.1749)^{*}$ & $31.2 \%$ \\
intraclass correlation & $13.2 \%$ & $3(0.1521)$ & \\
\hline
\end{tabular}

$*_{\mathrm{p}}<0.05$, one-tailed; $\mathrm{N}($ practices $)=93 ; \mathrm{n}(\mathrm{GPs})=138$.

easily understood by the fact that the chance that a greater number of different drugs will be prescribed is higher when the number of prescriptions is higher. A second explanation concerns the role of specialist initiated prescription that is subsequently followed by repeat prescriptions by GPs, a well known phenomenon in the Netherlands. This might vary between GPs because GPs who prescribe more usually also refer more to hospital consultants [35]. Therefore high prescribing GPs might also prescribe more repeat prescriptions initiated by specialists, that often deviate from (GP-)guidelines. An additional explanation for the relationship with prescriptions per patient may be that a broader drug repertory increases the inclination to prescribe because it increases the therapeutic possibilities of the doctor. The causal direction is difficult to infer from cross-sectional data as used by us. This is, of course, a limitation of this study.

A further limitation of our research is that the possibility of multicollinearity cannot completely be ruled out. Although the correlations between the independent variables are below the threshold level of .60 the correlations with non-urbanized areas (.55) and dispensing practice (.43) come close to the threshold. In dispensing practices prescriptions of GPs dispensed by the practice cannot be separated from specialist prescriptions. Removing the 14 dispensing GPs from the analysis lowered the coefficients a bit but did not change our overall conclusion.

GPs working in partnerships did not appear to have a broader range when controlled for other variables. This seems surprising, because we know from previous research that GPs in group practices have a broader range. We expected to see this also on individual level since their patients more often switch between GPs in group practices. Table 3 shows that GPs in group practice more often use oral information sources and receive fewer representatives of the pharmaceutical industry. On the other hand, working in a group practice is often associated with a stronger orientation to esteem by colleagues and to professional guidelines, leading to more rational prescription behaviour and therefore to a lower range[36,37]. The more frequent use of oral information (which will often be from colleagues) may point to this (see table 3 ). This might neutralize the range-broadening effects of patients switching between doctors.

Contrary to our expectations, we did not find any statistical relationship with factors associated with the composition of the practice or with the closely linked factor of the location of the practice. These were, in fact, proxy-indicators for differences in morbidity. This brings us to the second limitation of the study, which is that we did not take the diagnosis underlying the prescriptions into account. As a follow-up to this study, we recommend an analysis of the relationship between range and rational prescribing, taking diagnosis and comorbidity into account. This would also provide better opportunities to link the range of drugs prescribed to guidelines. A more specific followup study would be to investigate how computerized decision support systems affect the range of drugs prescribed.

Further and more detailed research is necessary into the differences between therapeutic main groups and subgroups with regard to the percentages of available drugs prescribed. We would hypothesize that GPs have a greater inclination to switch to other drugs in therapeutic groups where side-effects play an important role (i.e. hormonal contraceptives). The same could be true of therapeutic drugs with limited or variable effectiveness (i.e. antifungals for dermatological use). This is the grey area where representatives of the pharmaceutical industry play a role, 
stressing the advantages of their products compared to other products, in the form of fewer side-effects and better results.

\section{Conclusion}

We conclude that the range of drugs prescribed is a useful concept that could be used in addition to prescribing volume in research into prescription behaviour, especially when information concerning the indication is lacking. Restriction of the range of drugs as a policy instrument needs more thorough underpinning by means of further analysis of both quality and cost correlates of a smaller range of drugs prescribed.

\section{Competing interests}

The author(s) declare that they have no competing interests.

\section{Authors' contributions}

DDB participated in designing the study, did the final data analysis and drafted the final manuscript. DC prepared the data, did preliminary analysis and wrote the preliminary report. ERH participated in designing the study and helped in the interpretation of the data. LVD analyzed specifically the explanatory variables. PG helped in the design of the study and co-drafted the manuscript. All authors read and approved the final manuscript.

\section{Acknowledgements}

The authors thank Peter Spreeuwenberg for his help in performing and interpreting the multilevel analysis.

\section{References}

I. Coffie D, Van Dijk L, De Bakker DH, Dijkers F: "Mag blijvend herhaald worden": een voorstudie naar herhaalreceptuur in Nederland [An explorative study of repeat-prescribing in the Netherlands]. Utrecht, NIVEL; 2000.

2. Westert GP, Verkleij H, (eds): Dutch Health Care Performance Report 2006. Bilthoven, RIVM; 2006.

3. De Laat E, Windmeijer F, Douven R: How does pharmaceutical marketing influence doctors' prescribing behaviour? The Hague, CPB Netherlands' Bureau for Economic Policy Analysis; 2002.

4. Kamps G, Stewart R, Van der Werf G, Schuling J, Jong BM: Adherence to guidelines of regional formulary. Fam Pract 2000, I 7:254-260.

5. Avery AJ, Walker B, Heron T, Teasdale SJ: Do prescribing formularies help GPs prescribe from a narrower range of drugs? A controlled trial of the introduction of prescribing formularies for NSAIDs. Br / Gen Pract 1997, 47:810-8I4

6. Bjerrum L, Bergman U: Wide variation in the number of different drugs prescribed by general practitioners. A prescription database study. Scandinavian Journal of Primary Health Care 2000, I 8:94-98.

7. Hill-Smith I: Sharing resources to create a district drug formulary: a countywide controlled trial. Br J Gen Pract 1996, 46(406):27I-275.

8. Denig P, Haaijer-Ruskamp FM, Zijsking DH: How physicians choose drugs? Soc Sci Med 1988, 27:|38|-| 386.

9. Bradley CP: Decision Making and Prescribing Patterns - a literature Review. Fam Pract 1991, 8:276-287.

10. Bjerrum L, Søgaard J, Hallas J, Kragstrup J: Polypharmacy in general practices differences between practitioners. Br J Gen Pract 1999, 49:195-198.
II. McCarthy M, Wilson-Davis K, McGavock H: Relationship between the number of partners in a general practice and the number of different drugs prescribed by that practice. $\mathrm{Br} J \mathrm{Gen}$ Pract 1992, 42:10-12.

12. Dybdahl T, Anderson M, Kragtstrup J, Kristiansen IS, Sondergaard J: General practitioners' adoption of new drugs and previous prescribing of drugs belonging to the same therapeutic class: a pharmacoepidemiological study. Br J Clin Pharmacol 2005, 60(5):526-533.

13. Taylor RJ, Bond CM: Change in the established prescribing habits of general practitioners: an analysis of initial prescriptions in general practice. Br J Gen Pract I991, 4I(347):244-248.

14. Denig P, Haaijer-Ruskamp FM, Wesseling H, Versluis A: Towards understanding treatment preferences of hospital physicians. Soc Sci Med 1993, 36:915-924.

15. Bradley CP: Factors which influence the decision whether or not to prescribe: the dilemma facing general practitioners. BrJ Gen Pract 1992, 42:454-458.

16. Wilson RPH, Hatcher J, Barton S, Walley $\mathrm{T}$ : Influences of practice characteristics on prescribing in fundholding and non-fundholding general practices: an observational study. BMJ I996, 3 13:595-599.

17. Haaijer-Ruskamp FM: Drug-utilization studies in the Netherlands. Pharmaceutisch Weekblad Scientific Edition 1990, I 2:91-96.

18. Prosser H, Walley T: New drug uptake: a qualitative comparison of high and low prescribing GPs' attitudes and approach. Fam Pract 2003, 20(5):583-59l.

19. Verheij RA: Explaining urban-rural variations in health: a review of interactions between individual and environment. Soc Sci Med 1996, 42:923-935.

20. Veehof L, Stewart R, Haaijer-Ruskamp F, Jong BM: The development of polypharmacy. A longitudinal study. Fam Pract 2000, I 7:261-267.

21. Van Dijk L, Florentinus S, De Jong A, Velthove K, Heerdink R, Kallewaard $M$ : Het voorschrijven van nieuwe geneesmiddelen in de huisartspraktijk: voorschrijfvolume en off-label voorschrijven [Prescribing new drugs in general practice: prescribing volume and off-label prescribing]. Utrecht, NIVEL; 2003.

22. Hamley JH, MacGregor SH, Dunbar JA, Cromarty JA: Integrating clinical pharmacists into the primary health care team: A framework for rational and cost-effective prescribing. Scott Med J 1997, 42:4-7.

23. Van Dijk L, De Bakker DH: Professionalization of Dutch PRGs and volume and costs of frequently prescribed drugs. Zeitschrift für Gesuntheitswissenschaften 2002, 10:292-304.

24. Hayes TM, Allery LA, Harding KG, Owen PA: Continuing education for general practice and the role of the pharmaceutical industry. Br J Gen Pract 1990, 40:510-512.

25. Florentinus S: New drugs in general practice: prescribing patterns and external influences. Utrecht University, PhD thesis, Department of Pharmcoepidemiology and Pharmacotherapy; 2006.

26. Muijrers PE, Grol RP, Sijbrandij J, Janknegt R, Knottnerus JA: Differences in prescribing between GPs: impact of the cooperation with pharmacists and impact of visits from pharmaceutical industry representatives. Family Practice 2005, 22(6):624-30.

27. Westert GP, Schellevis FG, de Bakker DH, Groenewegen PP, Bensing $\mathrm{JM}$, van der Zee J: Monitoring health inequalities through general practice. European Journal of Public Health 2005, I 5(I):59-65.

28. Anonymous: Anatomical Therapeutic Chemical (ATC) classification index. Oslo: WHO Collaborating Centre for Drug Statistics Methodology; I993.

29. Verheij RA, De Bakker DH, Reijneveld SA: GP income in relation to workload in deprived urban areas in the Netherlands. Before and after the 1996 pay review. European Journal of Public Health 200I, I I:264-266.

30. Snijders TAB, Bosker RJ: Multilevel Analysis: An Introduction to Basic and Advanced Multilevel Modelling. London: Sage Publishers; 1999.

31. Leyland AH, Groenewegen PP: Multilevel modelling and public health policy. Scandinavian Journal of Public Health 2003, 3 I :267-274.

32. Bergman U, Popa C, Tomson Y, Wettermark B, Einarson TR, Aberg $H$, Sjoqvist F: Drug utilization $90 \%$ - a simple method for assessing the quality of drug prescribing. European Journal of Clinical Pharmacology 1998, 54(2): I I 3- I I8.

33. Wettermark B, Bergman U, Krakau I: Using aggregate data on dispensed drugs to evaluate the quality of prescribing in 
urban primary health care in Sweden. Public Health 2006, I 20(5):45I-6I.

34. Muijrers PE, Janknegt R, Sijbrandij J, Grol RP, Knottnerus JA: Prescribing indicators. Development and validation of guidelinebased prescribing indicators as an instrument to measure the variation in the prescribing behaviour of general practitioners. European Journal of Clinical Pharmacology 2004, 60(10):739-746.

35. Huygen F], Mokking HG, Smits AJ, Van Son JA, Meyboom WA, Van Eijk JT: Relationship between the working style of general practitioners and the health status of their patients. $\mathrm{Br} J \mathrm{Gen}$ Pract 1992, 42: |4|-| 44 .

36. Freidson E: Professions of medicine: a study in sociology of applied knowledge New York, Harper \& Row; 1970.

37. Wolinsky FD, Marder WD: The organization of medical practice and the practice of medicine Ann Arbor: Health Administration Press; 1985.

\section{Pre-publication history}

The pre-publication history for this paper can be accessed here:

http://www.biomedcentral.com/1472-6963/7/132/pre pub

Publish with Bio Med Central and every scientist can read your work free of charge

"BioMed Central will be the most significant development for disseminating the results of biomedical research in our lifetime. "

Sir Paul Nurse, Cancer Research UK

Your research papers will be:

- available free of charge to the entire biomedical community

- peer reviewed and published immediately upon acceptance

- cited in PubMed and archived on PubMed Central

- yours - you keep the copyright

Submit your manuscript here:

http://www.biomedcentral.com/info/publishing_adv.asp 